\title{
ASSESSMENT OF MANAGEMENT OF NEUROPATHIC PAIN PATIENTS IN A
} TERTIARY CARE HOSPITAL

\author{
Akshay Kumar $\mathrm{SN}^{1}$, Bharathi DR ${ }^{1}$, Nataraj GR ${ }^{1}$, Brahmadi Shankar Reddy ${ }^{2}$, Abubaker \\ Siddiq 1
}

${ }^{1}$ Department of Pharmacology, SJM College of Pharmacy, SJM Campus, Chitradurga

${ }^{2}$ Department of Pharmacy Practice, RMES College of Pharmacy, Kalaburgi

Article Info: Received 07 May 2021; Accepted 28 June 2021

DOI: https://doi.org/10.32553/jbpr.v10i3.875

Corresponding author: Akshay Kumar SN

Conflict of interest statement: No conflict of interest

\begin{abstract}
Background: Neuropathic pain (NP) affects millions of people worldwide, and it is estimated that the prevalence among general population is $7-8 \%$. Chronic NP is more frequent in women compared to men and in patients above 50 years of age. Lower back, lower limbs, neck, upper lumbar and cervical painful radiculopathies are probably the most frequent sites of chronic NP.

Objectives: To assess the neuropathic pain \& prescription pattern, and management among NP patients.

Materials and Methods: A prospective observational study was conducted in general orthopaedics department of Basaveshwara Medical College Hospital and Research Centre, Chitradurga.

Results: In the present study 111 patients who were diagnosed with neuropathic pain were enrolled for the period AUG-2019 to MAR -2020. Females were found to be slightly more than males. The maximum predominant age group of both genders belongs to $40-59$ years. $57.66 \%$ lumbar radiculopathy NP patients diagnosed were more than cervical radiculopathy 42.34\%. Out of 236 total prescribed formulations for 111 patients, 17 active pharmaceutical ingredients with an average of 2 formulations per prescription were noticed. Prescription with combination therapy was common with more usage of pregabalin and mecobalamin followed by combinations of Non-Steroidal Antiinflammatory and Antipyretic Drugs (NSAIDs) for the management of NP. NP patients preferred the usage of topical oil, balm applicants and hydro therapy along with regular treatment.

Conclusion: The study concludes pregabalin and mecobalamin combination formulation is the most currently reliable medication in NP management and also defines additional therapy is the need along with the regular management of NP.

Keywords: Neuropathic pain, Cervical radiculopathy, Lumbar radiculopathy, Non-Steroidal Antiinflammatory and Antipyretic Drugs.
\end{abstract}

\section{Introduction}

The International Association for the Study of Pain (IASP) defines Neuropathic pain (NP) as "pains arising from disease or injury to the peripheral or central nervous systems and from dysfunction of the nervous system. ${ }^{1}$
As per World Health Organization (WHO) survey on primary care patients, the prevalence of chronic pain from India was reported as $19 \% .^{2}$ Sleep disturbances, anxiety, depression are frequent and severe in-patients with NP. ${ }^{3}$ 
The management of NP generally focuses on treating symptoms because the cause of the pain can be rarely treated. Determining the cause of a pain is essential to good management. Antidepressants and antiepileptics are the most studied drugs in NP.,

\section{Methodology}

\section{Materials and methods:}

- Study Design: A Prospective observational Study.

- Study Site: The study was conducted in general orthopaedics, Basaveshwara Medical College Hospital and Research Centre, Chitradurga.

- Study Period: The study was conducted for a period of 8 months.

\section{Inclusion Criteria:}

- Subjects of both Genders.

- Age group between 26-75 years.

- Subjects included with Monotherapy as well as Polytherapy.

- Subjects with Primary and Secondary Neuropathic pain.

\section{Exclusion Criteria:}

- Previously diagnosed with Epilepsy.

- Those who are on Cancer treatment.

- Those who are on Psychiatric medications

Source of Data:
Demographics and medical history was collected from the interview with the patient or caretaker with their case sheets and their prescriptions.

\section{Study Procedure:}

The study was initiated after obtaining the ethical clearance of Institutional Ethics Committee (IEC) Ref:No.SJMCP/IEC/27/ 2018-19. Study subjects who satisfied the study criteria were enrolled into the study. After recruitment of subjects, each subject was explained clearly regarding the purpose of the study thereby obtained informed consent from them or caretakers. Demographic, treatment and additional therapy details of participants were collected in the pre-structured case record form (CRF).

The data obtained was analysed by using Microsoft Excel sheets and expressed in frequency and percentage.

\section{Results:}

In the present study 111 patients who were diagnosed with neuropathic pain were enrolled for the period AUG-2019 to MAR -2020. For further analysis of statistics we have considered 111 patients.

\section{Gender wise distributions of neuropathic pain patients}

Among the study population, 57 (51.35\%) were females and 54 (48.65\%) were males.

Results are graphically represented in figure no 1

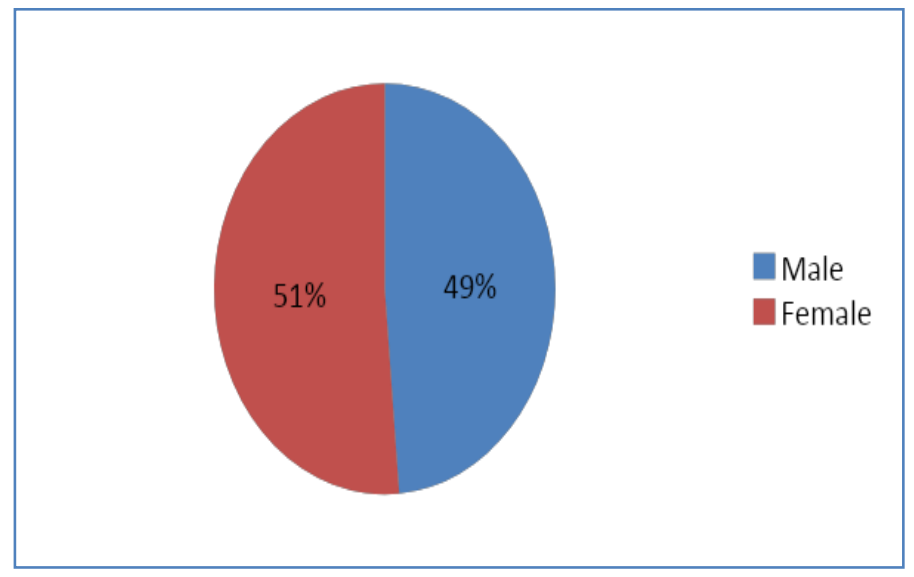

Figure 1: Showing Percentage of Gender wise distribution neuropathic pain patients 


\section{Age wise distribution of neuropathic pain patients}

Among the study population the patients were divided into three age groups. Majority of the patients belongs to Middle- Aged Adults 40-59 years (60) (54.05\%), followed by older age group 60-75 years (32) (28.83\%), were as younger adults 26-39 years comprised of (19) (17.12\%). Results are graphically represented in figure no 2

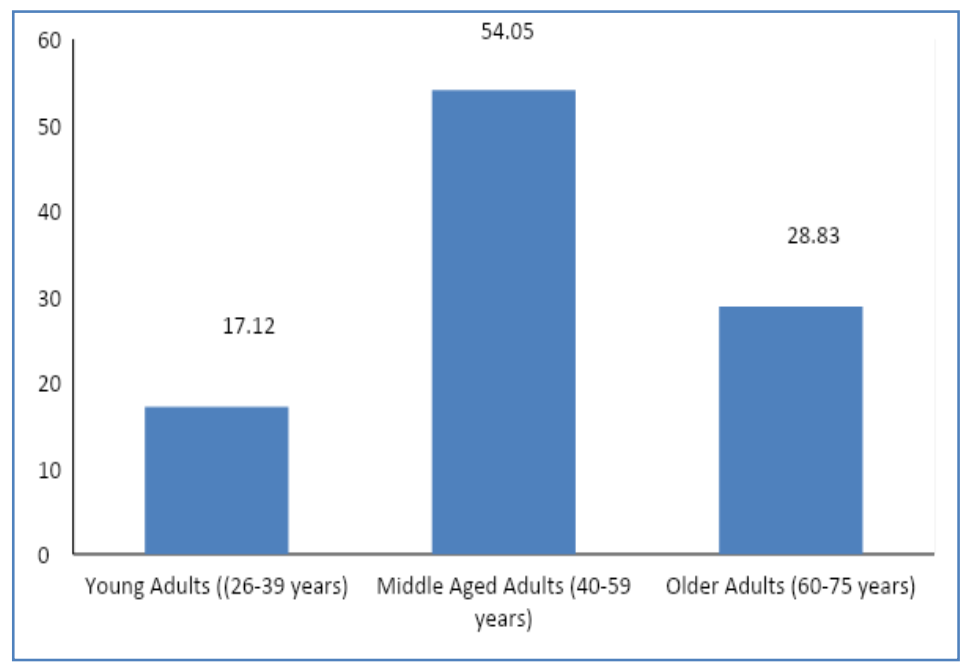

Figure 2: Showing Percentage of Age wise distribution of neuropathic pain. Patients

\section{Details of Diagnostic categorizations of neuropathic pain patients}

Out of 111 patients majority (64) (57.66\%) diagnosed with Lumbar radiculopathy followed by Cervical radiculopathy (47) (42.34\%). Results are graphically represented in figure no 3.

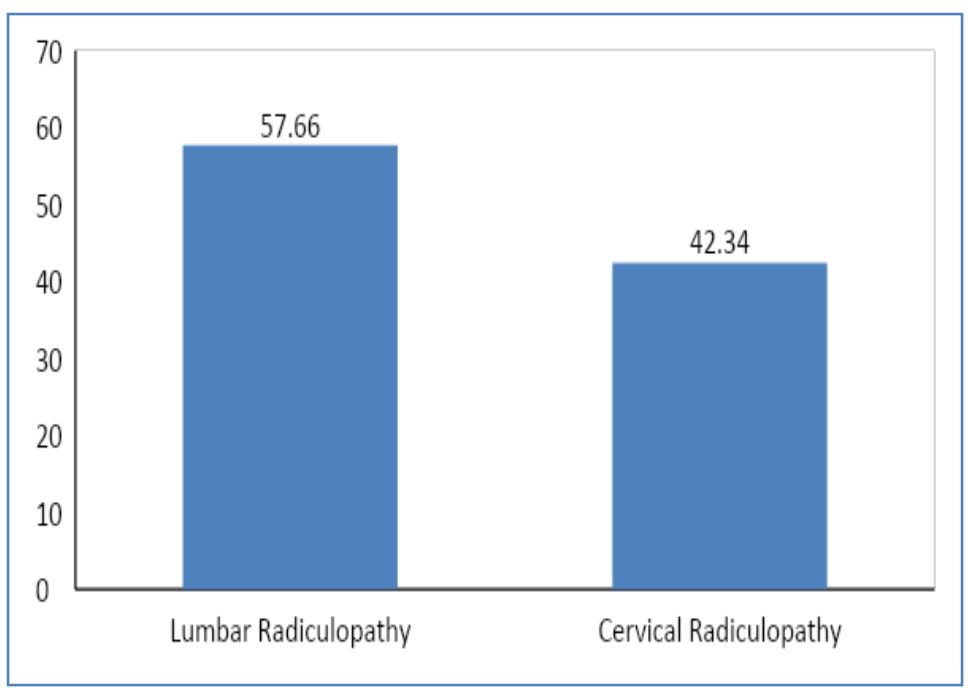

Figure 3: Showing Percentage of Details of Diagnostic categorizations of neuropathic pain patients

\section{Prescribing Pattern for management of neuropathic pain}

All the study participants 111 patients had been prescribed with various parameters like total number of formulation 236 with average (02.13) average formulation for prescription, Number of active drugs for all the formulation was 17 .Out of 111 patients 108 were prescribed combination therapy and the rest of the 3 were prescribed mono therapy. Results are graphically represented in figure no 4 


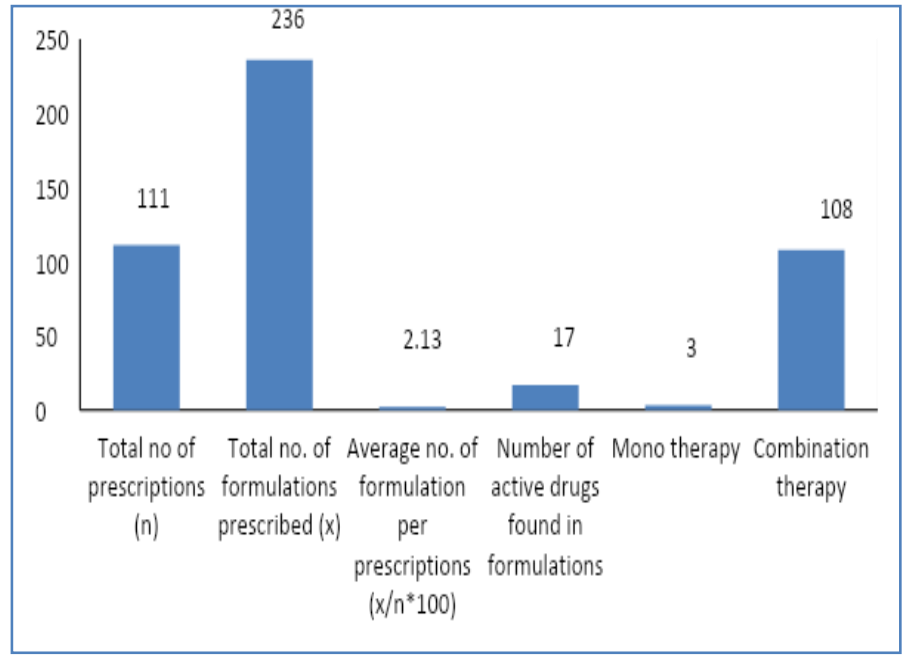

Figure 4: Showing Prescribing Pattern for management of neuropathic pain

\section{Drugs Usage pattern in management of neuropathic pain $(n=236)$}

Out of 111, (64) Patients were diagnosed with lumbar radiculopathy for which they were prescribed 138 medications with an average of 4.6 drugs per patient, majorly they were prescribed with Pregabalin+ Mecobalamin (28) (11.86), followed by Aceclofenac + Thiocolchicoside (27) (11.44\%), Pregabalin + Methylcobalamin + Pyridoxine + Folic acid + Benfotamine (24) (10.17\%), rest of the patients were prescribed with various NSAID'S combination like Aceclofenac paracetamol
(18) prescriptions, Etoricoxib and Etoricoxib + Thiocolchicoside (8) each.

The remaining 47 patients were diagnosed with Cervical radiculopathy (42.34\%) for which they were prescribed 98 medications as follows. Most preferred combination was Pregabalin + Mecobalamin (25) (10.59\%) followed by Aceclofenac paracetamol, Aceclofenac + Thiocolchicoside, Pregabalin + Methylcobalamin + Pyridoxine + Folic acid + Benfotamine, remaining patients are prescribed with less than $10 \%$. Results are graphically represented in figure no 5 and 6.

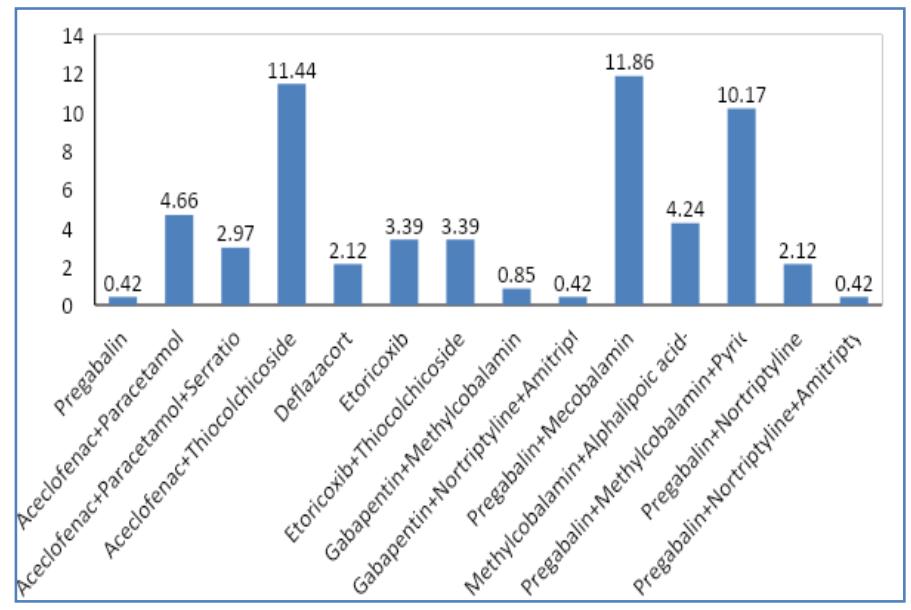

Figure 5: Showing Drugs Usage pattern in management of Lumbar Radiculopathy 


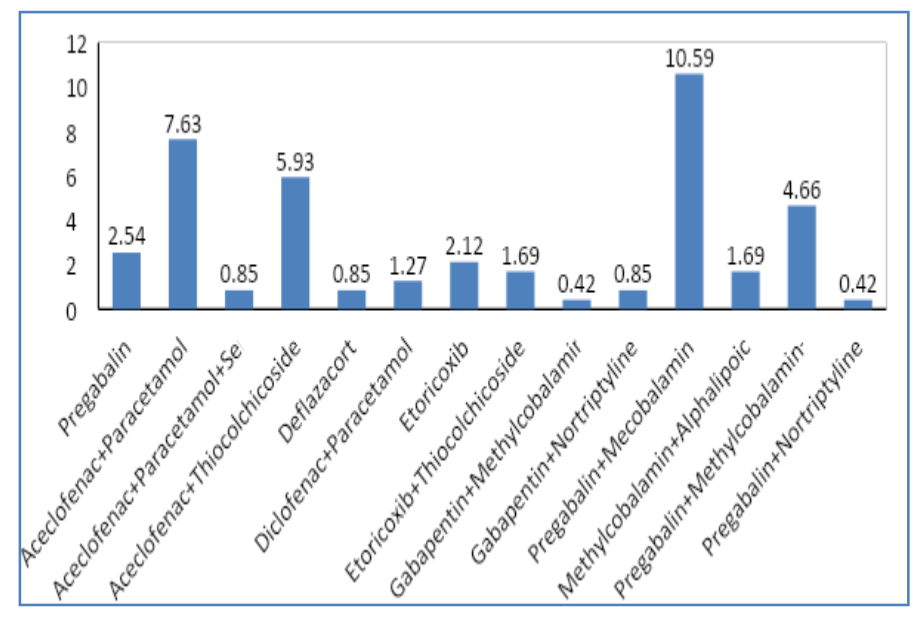

Figure 6: Showing Drugs Usage pattern in management of Cervical Radiculopathy

\section{Assessment of Additional management:}

\section{When the respondents were asked how do you manage your pain?}

$61(54.96 \%)$ had replied that they rely on pain relieving oils and balms followed by hot and cold water therapy along with pain reliving oils and balms 22 (19.82\%). While 16 (14.41\%) participants have mentioned that they do not relay on any such type of things. Results are graphically represented in figure no 7

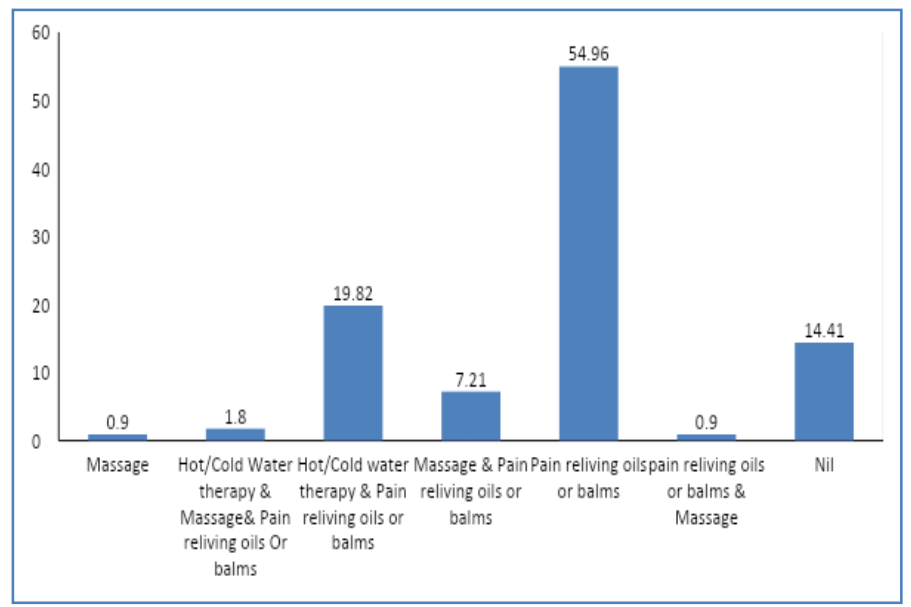

Figure 7: Showing percentage response to the question how do you manage your pain?

\section{Discussion:}

In the present study 111 patients who were diagnosed with neuropathic pain were enrolled. Demographic details of all patients like age, gender, physical activities, medication history, and their diagnosis pattern, management of pain were collected in suitable case record formats. $57(51.35 \%)$ were female and 54 $(48.65 \%)$ were male, with the maximum number falling under middle- aged group (4059 years) which were similar to a study conducted by Markman J et $\boldsymbol{a l}^{6}$ and gender ratio in our study females were more when compared to males which are similar to a study conducted by Shrestha R et al. ${ }^{7}$

The observation of our study revealed that more number combination therapy prescriptions $108(97.30 \%)$ followed by monotherapy $03(02.70 \%)$, which were very resemblance to study conducted by Sekhar Jena $\mathbf{S}$ et $\boldsymbol{a l}^{8}$ showing that polypharmacy was $(89.7 \%)$ compared to monotherapy (10.3\%). 
(Change) Our study findings have revealed that the most preferred combination is Pregabalin and Mecobalamin 53 (47.75\%) in NP of both Cervical and Lumbar radiculopathy, which are consistent with two studies Meta-analysis and Cochrane review. A Meta-analysis conducted by Onakpoya I J et $\boldsymbol{a l}^{9}$ and Cochrane review carried by Wiffen et $\boldsymbol{a l} .{ }^{10}$ However there are few previous studies that have shown that antiepileptics were prescribed majorly.Such one study conducted by Shrestha $\mathbf{R}$ et $\boldsymbol{a l}{ }^{7}$ as shown that anti-convulsants were $75 \%$ followed by NSAIDs. But here they have included NP as lower back pain as well as peripheral NP apart from radiculopathy. Additional management of NP by patients revealed the usage of topical oil, balm applicants and hydro therapy, along with regular treatment.

\section{Conclusion:}

The study concludes pregabalin and mecobalamin combination formulation is the most currently reliable medication in NP management and also defines additional therapy is the need along with the regular management of NP.

\section{Acknowledgement:}

The authors are grateful to the Dr. Bharathi D.R, Principal and all the Faculty of Department of Pharmacology, SJM College of Pharmacy, Chitradurga.

\section{References:}

1. Scadding J. Neuropathic Pain. Advances in clinical neuroscience and rehabilitation. 2003; 3(2):1-4.

2. Dutta D, Dalai CK, Roy S, Naskar C, Bhattacharyya D. Drug utilization pattern in a pain clinic of a tertiary care teaching hospital in Eastern India. Indian Journal of Pain 2013; 27(3):142-46.

3. Colloca L, Ludman $\mathrm{T}$, Bouhassira $\mathrm{D}$, Baron R, Dickenson AH, Yarnitsky D.
Neuropathic pain.Nat Rev Dis Primers.20017; 3(17002):1-45.

4. Torrance N, Smith BH, Bennett MI, Lee AJ. The Epidemiology of Chronic Pain of Predominantly Neuropathic Origin. Results From a General Population Survey. The Journal of Pain, 2006; 7(4):1-9.

5. Yalcin I, et al. $\beta 2$-Adrenoceptors are critical for antidepressant treatment of neuropathic pain. Ann Neurol. 2009; 65:218-225.

6. Markman J, Resnick M, Greenberg S, Katz N, Yang R, Scavone J et al. Efficacy of pregabalin in post-traumatic peripheral neuropathic pain: a randomized, doubleblind, placebo-controlled phase 3 trial. Journal of Neurology. 2018; 265(12):2815-2824.

7. Shrestha R, Silwal P, Basnet N, Shakya Shrestha S, Shrestha R, Pokharel BR. A prospective study of commonly prescribed drugs in the management of neuropathic pain and its medication adherence pattern. Kathmandu Univ Med J 2016; 53(1):47-53.

8. Sekhar jena S, Jena M, Patro N, Mishra S, Panda M, Dash M. Patterns of prescription and ADR monitoring of drugs in the management of neuropathic pain in a tertiary care teaching hospital. International Journal of Pharmacy and Pharmaceutical Sciences.2014; 6(10): 246-251.

9. Onakpoya I, Thomas E, Lee J, Goldacre B, Heneghan C. Benefits and harms of pregabalin in the management of neuropathic pain: a rapid review and meta-analysis of randomised clinical trials. BMJ Open. 2019; 9(1):e023600.

10. Wiffen PJ, Derry S, Moore RA, et al. Antiepileptic drugs for neuropathic pain and fibromyalgia - an overview of Cochrane reviews. Cochrane Database Syst Rev 2013; 11:CD010567. 